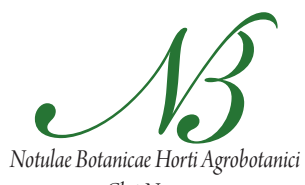

Clij-Napoca

\title{
Evaluation of Greenhouse Gas Emission from Animal Manure Using the Closed Chamber Method for Gas Fluxes
}

\author{
Sebastian-Călin VAC ${ }^{*}$, Gabriela-Emilia POPIȚA², Nicolae FRUNZETI², Antoanela POPOVICI ${ }^{3}$ \\ ${ }^{1}$ University of Agricultural Sciences and Veterinary Medicine, Faculty of Agriculture, 3-5 Calea Mănăş̆tur \\ Street, 400372,Cluj-Napoca, Romania; calinvac@yahoo.com (*corresponding author) \\ ${ }^{2}$ Babeş Bolyai University, Faculty of Environmental Science and Engineering, 30 Fântânele \\ Street, 400294 Cluj-Napoca, Romania; gabi.popita@yahoo.com \\ ${ }^{3}$ Tehnical University, Faculty of Materials and Environmental Engineering, 103-105 Bd. Muncii Street, 400641 Cluj-Napoca, Romania
}

\begin{abstract}
Animal manure is an important source of anthropogenic GHG (greenhouse gas): methane $\left(\mathrm{CH}_{4}\right)$, nitrous oxide $\left(\mathrm{N}_{2} \mathrm{O}\right)$ and carbon dioxide $\left(\mathrm{CO}_{2}\right)$. The livestock contributes with $37 \%$ of global $\mathrm{CH}_{4}$ emission. The sources of $\mathrm{GHG}\left(\mathrm{CO}_{2}\right.$ and $\left.\mathrm{CH}_{4}\right)$ are the liquid manure or slurry storage and the compact solid manure. Measurement systems of GHG emission are important for the selection of the appropriate technology. By using the closed chamber method for soil, landfills, volcanoes etc., the present study evaluates the estimation of total emissions of methane and carbon dioxide from an experimental farm in Cluj County, Romania. The investigated area covered with sheep solid manure was about $579 \mathrm{~m}^{2}$ and $\sim 5 \mathrm{~cm}$ thick, for cattle was about $12 \mathrm{~m}^{2}$ and $5 \mathrm{~m}$ thick and for swine was about $1.5 \mathrm{~m}^{5}$ and $0.5 \mathrm{~m}$ thick. The total methane emission measured for sheep manure was $0.83 \mathrm{t} \mathrm{CH}_{4} /$ year and for cattle manure was $0.185 \mathrm{t} \mathrm{CH}_{4} /$ year. The total carbon dioxide emission measured for sheep manure was $61.3 \mathrm{t} \mathrm{CO}_{2} /$ year and for cattle manure was $4.7 \mathrm{t} \mathrm{CO}_{2} /$ year. The measurement for pigs manure was high and this could be due to the freshness of the manure. The estimated emissions showed that a considerable amount of $\mathrm{CH}_{4}$ and $\mathrm{CO}_{2}$ is produced also by an experimental farm and an appropriate management of manure is important for reducing greenhouse gas. In this respect, we believe that the future solution for a green economy is to use manure in biogas plants.
\end{abstract}

Keywords: carbon dioxide, greenhouse gas emissions, manure, methane

\section{Introduction}

Currently, a lot of attention is given to environmental management in the intensive livestock farming, due to the environmental impact caused by the agriculture. According to Romanian legislation are considered greenhouse gases the following: carbon dioxide $\left(\mathrm{CO}_{2}\right)$, methane $\left(\mathrm{CH}_{4}\right)$, nitrous oxide $\left(\mathrm{N}_{2} \mathrm{O}\right)$, hydro-fluorocarbons, perfluorocarbons and sulfur-hexafluoride (SF6) (GD 780, 2006).

The total amount of produced manure at a farm, for each type of animal can be estimated as the average between the amount of produced manure per animal, and the number of animals (IPCC, 2006). Liquid manure or slurry storage and the compact solid manure are important sources of GHG components $\left(\mathrm{CO}_{2}\right.$ and $\left.\mathrm{CH}_{4}\right)$ (IPCC, 2001). The livestock contributes with $37 \%$ of global $\mathrm{CH}_{4}$ emission (IPCC, 2001).

The manure management is estimated as one of the primary sources of methane from agricultural emissions (Pattey et al., 2005). The composition of manure depends of the animal's dietary regime and the environmental conditions in which the fermentation processes occurred, and generally the manure is composed by different amount of organic material and water (Flynn et al., 2007). Different parameters of the manure $\left(\mathrm{pH}, \mathrm{NH}_{4}+\right)$ may contribute to the production of different amounts of methane (Park $e t$ al., 2006). The amount of produced methane is influenced by climate (temperature and rainfall) and by manure management (Jun et al., 1996). The storage of manure has a significant contribution to global methane emissions (Møller et al., 2004).

In Romania, according to the NIR (National Inventory Report) of GHG Inventory, in 2010, the agriculture sector accounted for $13.79 \%$ of the total GHG emissions. As reported, in 2010, $\mathrm{N}_{2} \mathrm{O}$ emissions contribution from the agricultural sector was $51.98 \%\left(\mathrm{CO}_{2}\right.$ equivalent emissions), followed by the $\mathrm{CH}_{4}$ emissions ( $48.02 \% \mathrm{CO}_{2}$ equivalent emissions). The enteric fermentation represented $45.14 \%$ from the contribution of the sub-sectors in the total GHG emissions from agriculture, while the manure management contribution was $6.86 \%$ (NIR, 2012).

Emissions from agriculture are often diffuse and hard to measure, so models are created to estimate them when the measurements are not possible. The best available techniques are focused on issues relating to the environment associated with the intensive rearing of poultry and swine and the priority are the emissions of ammonia $\left(\mathrm{NH}_{3}\right)$, also emissions of $\mathrm{N}$ and $\mathrm{P}$ in soil and water (groundwater or surface) (Proorocu, 2008). 
The GHG reducing emissions, under Kyoto Protocol is also a very important issue. The Kyoto Protocol Framework considered that all stages of manure management: collection, storage, treatment and field application to have a significant potential in GHG emission reduction (Karmakara et al., 2007; Kyoto Protocol, 1998).

One of the solutions to reduce GHG emissions is to promote RES (renewable energy sources); in this case, biogas plants. Among alternative energy sources, biogas technology, uniquely, can produce energy from materials whose storage present environmental hazards today. The green certificates obtained by the support scheme, make the investments in this area more accessible and increase the return on investment (Vac, 2012).

Therefore, the present study approaches the greenhouse gases emissions provided from solid manure in livestock farming, in order to demonstrate the sustainability of green investitions. For the study, an experimental farm from Turda, Cluj County, Romania, was chosen. The methane and carbon dioxide emission from animal manure were quantified with in situ measurements, by using the closed chamber method.

The regular national inventory emission is based on IPCC estimation method (GD 1570, 2007) which is not an experimental one. This experimental method was applied based on the author's experience versus the estimation method, namely that the experimental method is closer to the environmental local factors (climate, geographic indicators, customs etc.) than the estimation one (Popita, 2012).

The aim of the study is to promote the experimental method and to prove that even an experimental farm contributes to the GHG emissions. If the stakeholders would know exactly their activity emissions, a financial plan regarding the investments into a biogas plant could be made, as an advantage of both: stakeholder and environment.

\section{Materials and methods}

\section{The site location}

This study is focused on field measurement of $\mathrm{CH}_{4}$ and $\mathrm{CO}_{2}$ emissions on cows, sheep and swine's manure from an experimental farm in Turda, Cluj County, Romania (46 $34^{\prime \prime} 58.36^{\prime} \mathrm{N}$ and $23^{\circ} 47^{\prime \prime} 10.09^{\prime} \mathrm{E}$ ). The farm belongs to the University of Agricultural Sciences and Veterinary Medicine and it is situated in the South-Western part of Cluj County (Fig. 1).

For this study, the manure resulted from the raising of maximum (under the capacity of the farm) 400 swines, 600 sheep and 10 cows was taken into account.

\section{The emissions measurements}

The total emissions of methane and carbon dioxide were estimated by using the closed chamber method (Fig. 2). This is the most frequently used method for the measurement of gas fluxes from different environments such as landfills, soil, volcanoes and the method is widely described in the literature (Padron et al., 2008; Frunzeti and

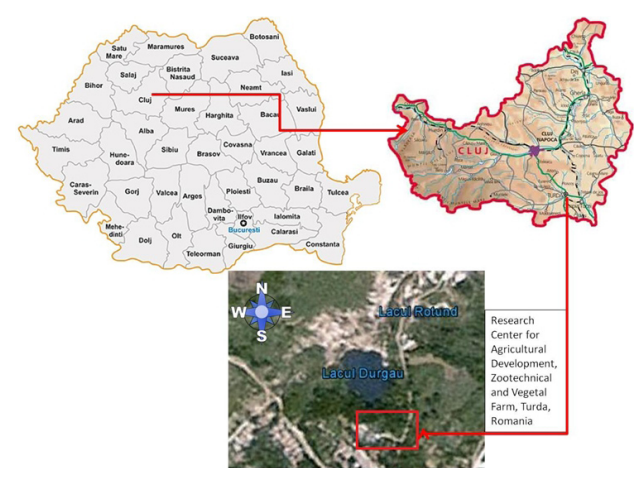

Fig. 1. The experimental farm location in Turda, Cluj County, Romania (Google Earth)

Baciu, 2012). The authors applied this method for the solid manure as a new and easy possibility to measure the GHG emissions from livestock.

The measurements were made with the portable device used for the flux measurement (diffusion) (Fig. 3). The components of the portable device are the following: accumulation chamber with separate detectors for methane and carbon dioxide, pump, batteries, motherboard and palmtop.

The device is based on a system of methane detection sensors (with lower detection limit of $1 \mathrm{ppm}$ and $1 \mathrm{ppm}$ resolution), data being transmitted through wireless network to a Palmtop PC. The methane sensor includes three detectors: a semiconductor detector (range 0-2,000 ppmv, detection limit 1 ppmv, resolution 1 ppmv), a catalytic detector (range 2,000 ppmv $-3 \% \mathrm{v} / \mathrm{v}$ ) and a thermal conductivity (range $3-100 \% \mathrm{v} / \mathrm{v}$ ) detector. The detector for $\mathrm{CO}_{2}$ is an infrared sensor with double beam (LI-COR) with a range of 0 to 20,000 ppmv (Popita, 2012).

Data is stored and the calculated flow (calculations are based on a linear regression) is displayed in real time. The system detects low methane flow (the order of several tens of $\mathrm{mg} \mathrm{CH}_{4} \mathrm{~m}^{-2} \mathrm{day}^{-1}$ in 10-15 minutes) (Popita, 2012).

The closed chamber method is easy to operate and useful for addressing research objectives needing spatial and temporal variability of fluxes at a small scale (Popita, 2012).

Chambers are very well suited for in situ measurements regarding surface-atmosphere trace gas exchange (Livingston and Hutchinson, 1995). The method assumes sealing the emitted gas which accumulates inside the chamber (Abichou et al., 2006).

To measure the flow of methane and carbon dioxide, the accumulation chamber was located on the solid manure in the established measurement points, ensuring that it is well insulated from the influence of atmospheric air. The measurement of the two gas fluxes is performed by placing the chamber on the surface of the manure, with no leaks, for approximately 2-4 minutes. Between measure- 
578

ment intervals, the gas is trapped into the accumulation chamber and the pump guided it through the detectors of methane and carbon dioxide, which transmit the recorded data to the portable computer.

Flux Manager, the software installed on the laptop, allows the recording of the flow curves of methane and carbon dioxide in real time and flow calculation. This information is also stored into the memory card, which can

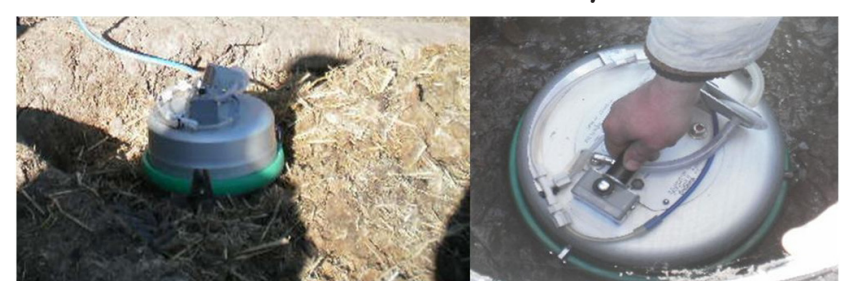

Fig. 2. The portable device for the methane and carbon dioxide measurements

be used later on another computer for analysis (Popita, 2012).

The structure of the portable device used for the measurements was represented in Fig. 3.

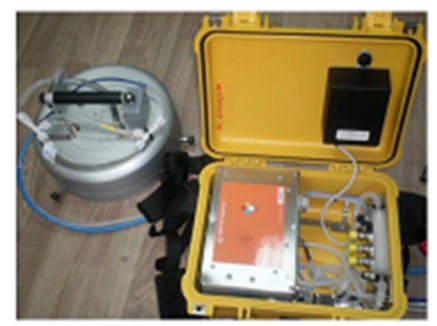

Fig. 3. The portable device used for the measurements

The linear regression can be used to calculate the gas flux by the equation, if the rate of increase in gas concentration inside the chamber is constant (Livingston and Hutchinson, 1995):

$$
F=\frac{V_{c}}{A_{c}} \times \frac{c_{2}-c_{1}}{t_{2}-t_{1}}
$$

where: $V_{c}\left(m^{3}\right)$ is the volume of the chamber; $A_{c}\left(m^{2}\right)$ is the footprint area of the chamber; $\mathrm{c}_{1}$ and $\mathrm{c}_{2}\left(\mathrm{mg} \cdot \mathrm{m}^{-3}\right)$ are gas concentrations at time $t_{1}$ and $t_{2}$ respectively (days).

The Flux Manager Software application is controlling the portable device and it can measure the $\mathrm{CH}_{4}$ and $\mathrm{CO}_{2}$ fluxes in $\mathrm{ppm} / \mathrm{sec}$.

The values were transformed from $\mathrm{ppm} / \mathrm{sec}$ to $\mathrm{g} \cdot \mathrm{m}-2$. day $^{-1}$, using the following equation:

$$
F=\frac{86400 \cdot P \cdot V}{10^{6} \cdot R \cdot A \cdot(T+237)} \cdot M \cdot 1000 \cdot a
$$

where: $\mathrm{F}$ is the flux of methane or carbon dioxide $\left[\mathrm{g} \cdot \mathrm{m}^{-2}\right.$ - day $\left.^{-1}\right]$; $\mathrm{P}$ is the barometric pressure [ $\left.\mathrm{mBar}, \mathrm{hPas}\right] ; \mathrm{R}$ is the universal gas constant, $0.08314510[(\mathrm{barL}) / \mathrm{K}] / \mathrm{mol} ; \mathrm{V}$ is the volume of the accumulation chamber; $\mathrm{A}$ is the area of the accumulation chamber; $\mathrm{T}$ is the temperature in ${ }^{\circ} \mathrm{C}$; a is the angular coefficient $[\mathrm{ppm} / \mathrm{sec}] ; \mathrm{M}$ is the molecular weight of the gas $\left(\mathrm{CH}_{4}=16\right.$, and $\left.\mathrm{CO}_{2}=44\right)$.

According to the Guidance on monitoring landfill gas surface (USEPA, 1986), the number of flux measurements which is required from an area depends on the size of the investigated area, and can be evaluated using the following formula:

where: $\mathrm{n}$ is the required number of field measurements

$$
n=6+0.15 \sqrt{Z}
$$

and $\mathrm{Z}$ is the size of the investigated area $\left(\mathrm{m}^{2}\right)$.

The manure surface for sheep was $579 \mathrm{~m}^{2}$, therefore, the required number of measurements was $\sim 10$. In order to improve the quality of the results, a number of 12 measurements were performed.

For cattle the investigated area was $12 \mathrm{~m}^{2}$, so the required number of measurements was $\sim 7$, and here a number of 5 measurements were performed. The total gas emission was estimated by multiplying the average value by the surface area.

The swine manure was stored in a tank, with a small surface about $1.5 \mathrm{~m}^{2}$. For this reason, two measurements were made. The manure was fresh and the values were very high. The measurements need to be repeated to can assure the accuracy of the estimated value of gas emission.

For sheep manure, the total output of $\mathrm{CH}_{4}$ and $\mathrm{CO}_{2}$ from the measured area was derived from Surfer 10 software developed by Golden Software, by using the Natural Neighbor interpolation. This method is well suited for irregularly spaced points with heterogeneous fluxes (Frunzeti and Baciu, 2012).

\section{Results and discussion}

For sheep, the emission calculated for the surface of $579 \mathrm{~m}^{2}$ (the average thickness of the manure was about 5 $\mathrm{cm}$ ) were: $61.3 \mathrm{t} \mathrm{CO}_{2} /$ year and $0.83 \mathrm{t} \mathrm{CH}_{4} /$ year.

The statistical parameters for $\mathrm{CO}_{2}$ and $\mathrm{CH}_{4}$ flux for the sheep manure was presented in the Tab. 1 . The values for carbon dioxide are $\sim 80$ times higher than for methane. The values of the kurtosis show if the data has a normal distribution. The skewness shows if the curves are symmetrical or not and the kurtosis if the curves are peaky.

The contour surface map for the measurements performed inside the sheep stable produced by using Surfer software is presented in Fig. 4. The map includes the distribution of measuring points and flux values in $\mathrm{g} \cdot \mathrm{m}-2 \cdot \mathrm{day}^{-1}$. The values of the carbon dioxide fluxes were higher than methane fluxes (Fig. 4 and Tab. 1). Carbon dioxide and methane fluxes were heterogeneous distributed, but the areas with the highest carbon dioxide fluxes corresponded with the areas with the highest values for methane fluxes, with a mean value of $3.78 \mathrm{~g} \mathrm{~m}^{-2} \mathrm{day}^{-1}$ for methane and 
$276.5 \mathrm{~g} \mathrm{~m}^{-2}$ day $^{-1}$ for carbon dioxide (Tab. 1). As an example, the area located in the South-Western part of the stable shows the highest values for both carbon dioxide and methane fluxes, while the area located in the north-eastern side shows the lowest values of the gas fluxes. The highest values may indicate a high thickness of sheep manure, while the lower values may indicate areas where the manure was scarce. The good correlation between these two fluxes may indicate that both carbon dioxide and methane fluxes come from the same sources, in this case from sheep manure.

Tab. 1. The statistical parameters for $\mathrm{CH}_{4}$ and $\mathrm{CO}_{2}$ flux for the sheep manure

\begin{tabular}{ccc}
\hline & \multicolumn{2}{c}{ Flux } \\
\hline Parameters & $\mathrm{CH}_{4}$ & $\mathrm{CO}_{2}$ \\
\hline $\begin{array}{c}\text { Maximum value } \\
\left(\mathrm{g} \cdot \mathrm{m}^{-2} \cdot \text { day }^{-1}\right)\end{array}$ & 11.864 & 465.849 \\
\hline $\begin{array}{c}\text { Minimum value } \\
\left(\mathrm{g} \cdot \mathrm{m}^{-2} \cdot \text { day }^{-1}\right)\end{array}$ & 0.304 & 148.545 \\
\hline Mean $\left({\left.\mathrm{g} \cdot \mathrm{m}^{-2} \cdot \text { day }^{-1}\right)}_{\text {Median }\left(\mathrm{g}^{-2} \cdot \mathrm{day}^{-1}\right)}\right.$ & 3.782 & 276.651 \\
\hline Standard deviation & 3.212 & 263.093 \\
\hline Skewness & 2.952 & 80.828 \\
\hline Kurtosis & 2.022 & 0.951 \\
\hline
\end{tabular}

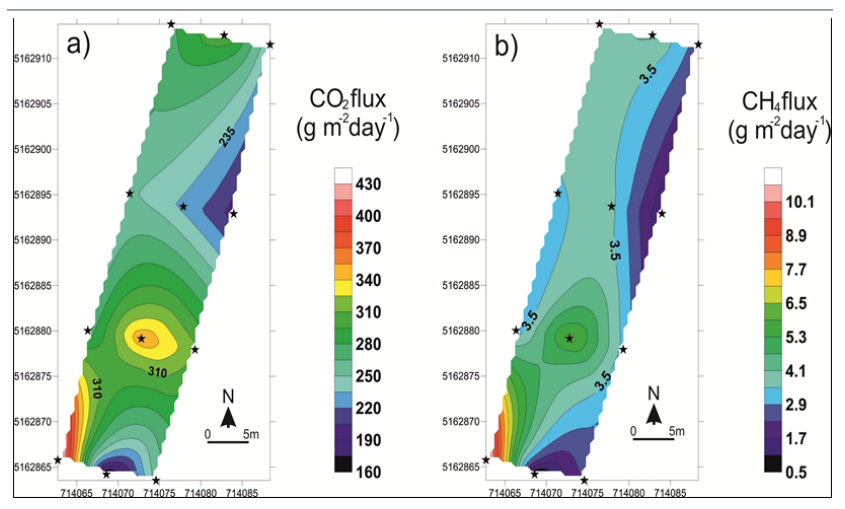

Fig. 4. The distribution of logarithmic values of $\mathrm{CO}_{2}$ (a) and $\mathrm{CH}_{4}$ flux (b) for sheep manure measurements; the stars indicate the location of the measurements

For cattle manure, due to the small number of cattle, the storage surface area covered is also reduced. Few measurements (Tab. 2) were performed, and the emission was calculated multiplying average value with the area covered with manure $\left(12 \mathrm{~m}^{2}\right)$. The average height of the manure was $\sim 5 \mathrm{~m}$. Consequently, the results of the gas emission were $0.185 \mathrm{t} \mathrm{CH}_{4} /$ year and $4.7 \mathrm{t} \mathrm{CO}_{2} /$ year

The mean of methane flux was $3.782 \mathrm{~g} \mathrm{~m}^{-2} \mathrm{day}^{-1}$ for sheep manure and $42.345 \mathrm{~g} \mathrm{~m}^{-2}$ day ${ }^{-1}$ for cattle. For $\mathrm{CO}_{2}$ the mean was $276.651 \mathrm{~g} \mathrm{~m}^{-2} \mathrm{day}^{-1}$ for sheep, and $1,083.461$ $\mathrm{g} \mathrm{m}^{-2}$ day $^{-1}$ for cattle. It was noticed that most of the mea- surements were clustered in the range up to $231 \mathrm{~g} \mathrm{~m}^{-2} \mathrm{day}^{-1}$ for $\mathrm{CO}_{2}$ and $2.41 \mathrm{~g} \mathrm{~m}^{-2}$ day $^{-1}$ for $\mathrm{CH}_{4}$. The negative of the kurtosis show that the data hasn't a normal distribution.

Tab. 2. The statistical parameters for $\mathrm{CH}_{4}$ and $\mathrm{CO}_{2}$ flux for the cattle manure

\begin{tabular}{ccc}
\hline & \multicolumn{2}{c}{ Flux } \\
Parameters & $\mathrm{CH}_{4}$ & $\mathrm{CO}_{2}$ \\
$\begin{array}{c}\text { Maximum value } \\
\left(\mathrm{g} \cdot \mathrm{m}^{-2} \cdot \text { day }^{-1}\right)\end{array}$ & 68.472 & $2,406.018$ \\
$\begin{array}{c}\text { Minimum value } \\
\left(\mathrm{g} \cdot \mathrm{m}^{-2} \cdot \text { day }^{-1}\right)\end{array}$ & 22.672 & 313.828 \\
\hline Mean $\left(\mathrm{g} \cdot \mathrm{m}^{-2} \cdot\right.$ day $\left.^{-1}\right)$ & 42.346 & $1,083.461$ \\
Median $\left(\mathrm{g} \cdot \mathrm{m}^{-2} \cdot\right.$ day $\left.^{-1}\right)$ & 39.736 & 962.721 \\
\hline Standard deviation & 17.840 & 704.522 \\
\hline Skewness & 0.484 & 1.560 \\
\hline Kurtosis & -1.140 & 3.472 \\
\hline
\end{tabular}

The total methane emission measured for sheep manure was $0.83 \mathrm{t} \mathrm{CH}_{4} /$ year and for cattle manure was 0.185 t $\mathrm{CH}_{4} /$ year. The total carbon dioxide measured emission for sheep manure was $61.3 \mathrm{t} \mathrm{CO}_{2} /$ year and for cattle manure was $4.7 \mathrm{t} \mathrm{CO}_{2}$ /year.

For swine was made one measurement (Tab. 3) on a very small surface $\left(1.5 \mathrm{~m}^{2}\right)$.

Tab. 3. The measurement for the swine manure

\begin{tabular}{ccc} 
No. of measurement & $\mathrm{CH}_{4}$ flux $\left(\mathrm{g} / \mathrm{m}^{2} /\right.$ day $)$ & $\mathrm{CO}_{2}$ Alux $\left(\mathrm{g} / \mathrm{m}^{2} /\right.$ day $)$ \\
\hline 1 & 479.3015 & $4,456.3635$ \\
2 & 398.5886 & $3,896.4785$
\end{tabular}

For swine manure because the storage area was too small, two measurements were performed and cannot conclude an estimated value for methane and carbon dioxide emission. The result of the measurement was very high, and this fact could have been due to the freshness of the manure.

The method used in this study for measuring the methane and carbon dioxide flux was applied in order to calculate the carbon dioxide and methane flux for the collected solid manure for different type of animals: cattle, swine, sheep. It is a method successfully applied in other areas such as: landfills, soil, volcanoes etc. A new method (correlated with another known method) and more studying is also needed for this area, to make a comparison between the results.

In literature, many authors studied different experimental methods to measure and estimate methane emissions for different type of animals manure. Storm et al. (2012) mentioned for ruminants the following methods: Animal calorimetric systems (the methane emission is calculated from flow and gas concentration in inlet and outlet air from the chamber where the animals are living); 
580

SF6 Tracer Technique (investigates the energy efficacy in free ranging cattle (Zimmerman, 1993); the use of the method to quantify the methane emission has been debated in some studies of Pinares-Patiño et al. (2008) and Pinares-Patiño et al. (2011); In Vitro Gas Production Technique for Methane Measurements (requires access to fresh rumen fluid, which is typically obtained from fistulated cows or other ruminants); The $\mathrm{CO}_{2}$ Technique (estimates methane emissions from livestock based on the use of $\mathrm{CO}_{2}$ as a tracer gas (Madsen et al., 2010)); Methods Based on Whole Buildings or Areas (can be divided into non-micrometeorological techniques and micrometeorological techniques defined as measuring fluxes of gas in the free atmosphere and relating these fluxes to animal emissions (Harper et al., 2011); Combined Feeder and $\mathrm{CH}_{4}$ Analyzer (is a patented system which combines an automatic feeding system with measurements of $\mathrm{CH}_{4}$ and $\mathrm{CO}_{2}$ ), proxy-methods (are correlating the methane emissions with parameters that can be measured in easily obtainable biological samples like milk or feces). Other methods for estimating the methane emissions are: the large dynamic chamber (Enishi and Osada, 2012), chambers made of aluminum which measured $10 \mathrm{~cm}$ tall used for flux measurement from swine slurry (Lovanh et al., 2010), closed chamber (test containers with flexible roof) methodology at a pilot-scale for measurements of gas emissions from cattle stored slurry (Rodhe et al., 2009).

When the measurements are not possible, the total emissions have to be assessed by IPCC method or methane models (Storm et al., 2012).

\section{Conclusions}

For the evaluation and prediction of the global warming impact on animal production it is important to develop a technology to estimate $\mathrm{CH}_{4}$ emission accurately from any type of animals. In this study we are looking for a general method to measure the methane and carbon dioxide emissions for any type of animal solid manure in order to calculate the methane and carbon dioxide quantities at national level.

The estimated emissions showed that a considerable amount of $\mathrm{CH}_{4}$ and $\mathrm{CO}_{2}$ is produced even by an experimental farm and an appropriate management of manure is important for reducing greenhouse gas. In this respect, we believe that the future solution is to use manure in biogas plants, for a green economy, which is an environmental good practice. Besides the environmental gain, the green certificates obtained by the support scheme make investments in this area more accessible and increase the return on investment.

The study revealed the importance of knowledge of the livestock impact, in order to help the stakeholders to choose the appropriate BAT (Best Available Techniques) technology, for their farm and region.

\section{References}

Abichou T, Chanton J, Powelson D, Fleiger J, Escoriaza S, Lei Y, Ster J (2006). Methane flux and oxidation at two types of intermediate landfill covers. Waste Manage 26:1305-1312.

Enishi O, Osada T (2012). Measurement method of GHG emission from ruminants and manure management. http:// www-gio.nies.go.jp/wgia/wg6/pdf/4-3-2\%20Osamu\%20 Enishi.pdf (accessed at 25/8/2013).

Flynn H, Smith P, Bindi M, Trombi G, Oudendag D, Rousseva $S$ (2007). Policy Incentives for Climate Change Mitigation Agricultural Techniques (PICCMAT). Brussels, 6/69.

Frunzeti N, Baciu C (2012). Diffuse $\mathrm{CO}_{2}$ emission at Sfanta Ana lake-filled crater (Eastern Carpathians, Romania). Procedia Environmental Sciences 14:188-194.

GD 780 (2006). Government Decision regarding the establishment of emissions trading in greenhouse gas emissions, as amended by GD 133 from 2010. Official Gazette no. 554 of 2006.

GD 1570 (2007). Government Decision regarding the foundation of National System for estimating anthropogenic emissions of greenhouse gases by sources and removals by sinks of carbon dioxide, regulated by the Kyoto Protocol. Official Gazette no. 26 of 2008.

Harper LA, Denmead OT, Flesch TK (2011). Micrometeorological techniques for measurement of enteric greenhouse gas emissions. Anim Feed Sci Technol Volumes 166-167, 227-239.

IPCC (2001). Guidelines for National Greenhouse Gas Inventories: Waste 2001, on line at: http://www.ipcc-nggip.iges. or.jp/public/2006gl/vol5.html (accessed at 15/06/2013).

IPCC (2006). Guidelines for National Greenhouse Gas Inventories, Volume 4: Agriculture, Forestry and Other Land Use, Chapter 10 Emissions from livestock and manure management, on line at http://www.ipcc-nggip.iges.or.jp/ public/2006gl/ pdf/4_Volume4/V4_10_Ch10_Livestock. pdf (accessed at 10/06/2013).

Jun P, Gibbs M, Gaffney K (1996). CH4 and N2O emissions from livestock manure, Good Practice Guidance and Uncertainty Management in National Greenhouse Gas Inventories, on line at: http://www.ipcc-nggip.iges.or.jp/public/ gp/bgp/4_2_CH4_and_N2O_Livestock_Manure.pdf (accessed at 18/06/2013).

Karmakara S, Lague C, Agnewc J, Landry H (2007). Integrated decision support system (DSS) for manure management: A review and perspective. Comput Electron Agr 57:190-201.

Kyoto Protocol (1998). Kyoto Protocol to the United Nations Framework Convention on Climate Change, on line at http://unfccc.int/resource/docs/convkp/kpeng.pdf (accessed at 14/06/2013).

Livingston GP and Hutchinson G (1995). Enclosure-based measurement of trace gas exchange: applications and sources of error p.14-52. In: Matson PA and Harriss RC (Eds.). Methods in Ecology, Biogenic Trace Gases: Measuring Emissions 
from Soil and Water. Blackwell Science, Cambridge, MA.

Lovanh N, Warren J, Sistani K (2010). Determination of ammonia and greenhouse gas emissions from land application of swine slurry: A comparison of three application methods. Bioresour Technolo 101:1662-1667, Madsen J, Bjerg BS, Hvelplund T, Weisbjerg MR, Lund P (2010). Methane and carbon dioxide ration in excreted air for quantification of the methane production from ruminants. Livest Sci 129:223-227.

Møller HB, Sommer SG, Ahring BK (2004). Methane productivity of manure, straw and solid fractions of manure. Biomass Bioenergy 26:485-495.

NIR (2012). National Environmental Protection Agency. National Inventory Report. Romania’s Greenhouse Gas Inventory 1989-2010 on line at http://www.anpm.ro/ upload/87231_NIR-NGHGI\%202012\%20V.\%202.1.pdf (accessed at 05/03/2013).

Padron E, Hernandez PA, Toulkeridis T, Perez NM, Marrero R, Melian G, Virgili G, Notsu K (2008). Diffuse $\mathrm{CO}_{2}$ emission rate from Pululahua and the lake-filled Cuicocha calderas, Ecuador. J Volcanol Geoth Res 176:163-169.

Park KH, Thompson AG, Marinier M, Clark K, Wagner-Riddle C (2006). Greenhouse gas emissions from stored liquid. Atmos Environ 40:618-627.

Pattey E, Trzcinski MK, Desjardins RL (2005). Quantifying the reduction of greenhouse gas emissions as a result of composting dairy and beef cattle manure. Nutr Cycl Agroecosys 72:173-187.

Pinares-Patiño CS, Holmes CW, Lassey KR, Ulyatt MJ (2008). Measurement of methane emission from sheep by the sulphur hexafluoride tracer technique and by the calorimetric chamber: Failure and success. Animal 2(1):141-148.
Pinares-Patiño CS, Lassey KR, Martin RJ, Molano G, Fernandez M, MacLean S, Sandoval E, Luo D, Clark H (2011). Assessment of the sulphur hexafluoride (SF6) tracer technique using respiration chambers for estimation of methane emissions from sheep. Anim Feed Sci Technol 166:201-209.

Popița GE (2012). Contributions to the efficiency of the household waste management systems (Case study: Cluj County). Babes-Bolyai University, Faculty of Environmental Science and Engineering. PhD Diss.

Rodhe L, Ascue J, Nordberg $\AA$ (2009). Emissions of greenhouse gases (methane and nitrous oxide) from cattle slurry storage in Northern Europe, IOP Conf. Series: Earth and Environmental Science 8012019 doi:10.1088/1755-1315/8/1/012019, http://iopscience.iop.org/1755-1315/8/1/012019/pdf/ ees9_8_012019.pdf (accessed at: 25/08/2013).

Storm IMLD, Hellwing ALF, Nielsen NI, Madsen J (2012). Methods for Measuring and Estimating Methane Emission from Ruminants. Animals 2:160-183; 2:10.3390/ ani2020160.

USEPA (1986). Measurement of gaseous emission rated from land surfaces using an emission isolation flux chamber. User's guide, EPA 600/8-86-008 (NTIS PB-223161). USEPA. Washington.

Vac SC (2012). Economic and financial feasibility of renewable sources of energy. University of Agricultural Sciences and Veterinary Medicine Cluj-Napoca, PhD Diss.

Zimmerman PR (1993). System for Measuring Metabolic Gas Emissions from Animals. US Patent 5, 265, 618. 